\title{
HEIDEGGER Y SUS MESES DE RECTORADO A LA LUZ DE LOS PRIMEROS CUADERNOS NEGROS (1931-1938), REFLEXIONES II-VI
}

\author{
IGNASI BOADA \\ Universitat Ramon Llull \\ (Barcelona)
}

\begin{abstract}
RESUMEN: La publicación de lo primeros Cuadernos negros invita a una relectura de la trayectoria de Heidegger en algunos aspectos fundamentales de su obra previa a 1931. En una primera parte del artículo nos centramos en aspectos fundamentales del recorrido vital y filosófico de Heidegger, muy especialmente en la amplitud y el significado de su ruptura con el catolicismo como elemento que condiciona su sentimiento de indigencia y la necesidad de un preguntar fundamental. En la segunda parte, centramos nuestra atención en textos de los Cuadernos negros correspondientes a los años de 1931 a 1933 para comprobar en qué sentido Heidegger vive en momentos cruciales de su vida bajo la influencia de lo que él llama seísmos subterráneos. El sentimiento de soledad en incomprensión que vive Heidegger se muestra en el hecho que, según él, nadie ha entendido Ser y tiempo.
\end{abstract}

PALABRAS CLAVE: Cuadernos negros; Heidegger; catolicismo; nacionalsocialismo; nihilismo.

\section{Heidegger and his months as rector in the light of the first Black Notebooks (1931-1938). Ponderings II-VI.}

ABSTRACT: The publication of the first volume of the Black notebooks invites us to reconsider some crucial aspects of Heidegger's books written before 1931. In the first part of this article we focus our attention on fundamental aspects of the life and philosophical evolution of Heidegger, especially in the extent and significance of his break with Catholicism as an element that exasperates his sense of spiritual penury and the need for a fundamental questioning. In the second part, we focus on the Black notebooks from 1931 to 1933 in order to check in what sense Heidegger lives at crucial moments of his life under the influence of what he calls «underground earthquakes». The feeling of loneliness by Heidegger is shown in the fact that, according to him, no one has understood Being and Time.

KEY WORDS: Black notebooks; Heidegger; catholicism; nationalsocialism; nihilism.

\section{INTRODUCCIÓN}

En el presente artículo nos proponemos tomar en consideración uno de los momentos más problemáticos de la vida y de la producción filosófica de Heidegger. Nos referimos a los meses que preceden inmediatamente la toma de poder por parte de Hitler (el 30 de enero de 1933) y a los meses sucesivos. Es importante recordar que prestamos atención a un período en el que el prestigio académico de nuestro autor era ya indiscutido. La publicación de Ser y tiempo (1927) lo había consagrado como una referencia clara no sólo en el panorama filosófico alemán, sino europeo. Heidegger no era ya solo un discípulo aventajado de Husserl; su figura no se identificaba ya solamente con el hecho de dar continuidad a la fenomenología de su maestro en Freiburg. Para aquellos que comprendían la importancia que tenía para él la pregunta por el sentido del ser como intención que guía su descripción fenomenológica 
existencial, comprendían también que no era un autor que pudiera ser alineado simplemente como pensador existencialista. Su pensamiento había llegado a definirse con un perfil propio y una autoridad que pocos se atrevían a cuestionar. Esto convirtió su posicionamiento en 1933 en una cuestión difícil y cargada de una grave responsabilidad. Como es sabido, este ha sido un tema ampliamente debatido durante los últimos años.

El inicio de la publicación de los Cuadernos negros es una razón de peso para volver a valorar este tema porque, sin lugar a dudas, saca por primera vez a la luz elementos de una importancia remarcable. El acceso a textos que Heidegger había elaborado durante más de cuatro décadas ha contribuido y contribuye a calibrar de nuevo el valor filosófico del posicionamiento de Heidegger en 1933 y en general de sus prioridades temáticas.

En este sentido querría introducir tres consideraciones de carácter previo:

i)-. La perspectiva de la publicación de los Cuadernos negros abrió la esperanza de arrojar cierta luz sobre la evolución del pensamiento y los elementos de reflexión que llevaron a Heidegger a sumarse al movimiento nacionalsocialista en los meses inmediatamente anteriores a la «Machtergreifung». Como es sabido, durante el semestre de invierno de 1932-1933 (esto es, de octubre a febrero) Heidegger obtuvo un permiso de la Universidad para dedicarse exclusivamente a su trabajo como investigador, por lo que la mayor parte del tiempo lo pasó muy aislado en Todtnauberg, en su refugio de trabajo. Una de las preguntas a las que invita esta circunstancia es la de cómo pueden coincidir unos meses de reflexión y trabajo solitarios con el período de tiempo que presuntamente se requería para aparecer entre sus colegas como una personalidad lo suficientemente afín al nacionalsocialismo como para ser el candidato más idóneo al cargo de rector en abril de 1933. Porque el hecho es que a principios de marzo de 1933, hay ya un consenso alrededor de Heidegger para que acceda a la máxima responsabilidad de la Universidad de Freiburg.

Por un lado, este consenso no fue improvisado. Hay que pensar que por parte de las nuevas autoridades supuso un discernimiento previo y un tiempo para cerciorarse de la afinidad política del candidato. Igualmente, la conclusión a la que llegaron sus colegas, en el sentido de verlo como el candidato más idóneo, no puede basarse en meras conjeturas, sino en el hecho de tener constancia de una cierta afinidad entre Heidegger y las nuevas autoridades.

Por otro lado tampoco hay elementos objetivos para afirmar que hasta la primavera de 1933 Heidegger se hubiera interesado de forma sostenida por cuestiones políticas, más allá de ciertas declaraciones privadas ${ }^{1}$.

Por su estilo, los Cuadernos negros abrían la posibilidad de ofrecer algunas claves para la comprensión de esta aproximación discreta pero efectiva de Heidegger a los entornos de influencia nacionalsocialista.

1 Cf. SAfranski, R., Ein Meister aus Deutschland, Fischer, Frankfurt a.M., 2000, p. 257. 
ii)-. En el año 2014 salió a la luz el contenido de determinadas expresiones inequívocamente antisemitas de algunas de las páginas de los Cuadernos negros. No es nuestra intención infravalorar la importancia de este hecho, especialmente porque suponen una novedad en relación a la información disponible sobre comportamiento y la actitud de Heidegger antes de la publicación de estos cuadernos ${ }^{2}$. No había pruebas evidentes de que Heidegger operara mentalmente con categorías antisemitas en el sentido hitleriano (racial, biológico, político) del término, al menos de forma sistemática. Se conocía un único texto con expresiones muy duras, el de la carta del 2 de octubre de 1929 a Victor Schwörer, el presidente de la organización de ayuda para científicos alemanes $^{3}$. Sin embargo los Cuadernos negros significan una novedad dramática y lamentable que contribuye aún más a cuestionar la calidad civil de su autor y a poner de relieve que su grado de participación en lo que podríamos llamar el sistema de valoración nazi fue seguramente más profundo de lo se pudo creer en el pasado. Se comprende, por lo tanto, que la recepción de estos controvertidos textos hasta ahora se haya centrado casi exclusivamente sobre este tema ${ }^{4}$.

2 Cf. Por ejemplo Arend, H.; Heidegger, M., Briefe 1925 bis 1975 und andere Zeugnisse, Klostermann, Frankfurt a.M. 1998, pp. 68-69.

3 «Lo que en mi certificado [se refiere a una beca solicitada por el Dr. Eduard Baumgarten, un sobrino de Max Weber] sólo podía aludir de manera indirecta, lo puedo decir ahora más claramente: lo que se trata no es ni más ni menos que del pensamiento insoslayable que estamos ante la disyuntiva de volver a avituallar a nuestra vida espiritual alemana con unas auténticas energías y con unos educadores arraigados en la tierra [bodenständige] o bien entregarla de manera definitiva a la creciente judaización en un sentido amplio y restringido del término. Sólo podremos encontrar de nuevo el camino si somos capaces, sin ruido ni discusiones infructuosas, procurar energías nuevas que se vayan desplegando...» . Ni Arendt ni nadie, excepto Victor Schwörer, tenían conocimiento de esta carta, escrita en 1929 y publicada por primera vez sesenta años más tarde, en 1989. Cf. Die Zeit r. 52, 22 Dezember 1989, «Die Verjudung des deutschen Geistes. Ein unberkannter Brief Heidegger's [2 Okt. 1929]» von Ulrich Sieg. La palabra clave que Heidegger emplea («judaización» - Verjudung) no aparece en los diccionarios, pero sí (exclusivamente) en Mein Kampf.

4 Expresiones como: «El judaismo mundial, instigado por los emigrantes a los que se permitió salir de Alemania, resulta en todas partes inaprensible y, en qualquier despliegue de poder, no tiene nunca necesidad de tomar parte en acciones de guerra, contra lo cual sólo nos queda sacrificar la mejor sangre de los mejores del propio pueblo», («Das Weltjudentum, aufgestachelt durch die aus Deutschland hinausgelassenen Emigranten, ist überall unfaßbar und braucht sich bei aller Machtentfaltung nirgends an kriegerischen Handlungen zu beteiligen, wogegen uns nur bleibt, das beste Blut der Besten des eigenen Volkes zu opfern.», Überlegungen XII-XV, in GSA 96, S. 262). O bién: «El incremento momentáneo del poder de los judíos tiene su fundamento en que la metafísica de occidente, principalmente en su despliegue moderno, ofreció el punto de desplegue inicial para la expansión de una racionalidad y capacidad de cálculo vacíos, creándose de esta manera, un refugio en el "espíritu" sin que los ámbitos de decisión ocultos se pudieran comprender» («Die zeitweilige Machtsteigerung des Judentums aber hat darin ihren Grund, daß die Metaphysik des Abendlandes, zumal in ihrer neuzeitlichen Entfaltung, die Ansatzstelle bot für das Sichbreitmachen einer sonst leeren Rationalität und Rechenfähigkeit, die sich auf solchem Wege eine Unterkunft im "Geist" 
iii)-. Sin ánimo de negar la importancia y la gravedad de las expresiones antisemitas a las que acabamos de aludir ni de la implicaciones filosóficas que conllevan, el hecho es que su protagonismo ha provocado que otras partes de los Cuadernos negros vinculadas a la producción filosófica, con temas relevantes de fondo que ayudan a comprender la evolución del pensamiento de Heidegger, sus prioridades filosóficas, la percepción de su momento histórico e incluso el sentido de fondo de su decisión en 1933 hayan quedado francamente eclipsadas. La existencia de esta dimensión más académica no constituye un capítulo aparte, en el sentido de que no tengan ninguna relación con los posicionamientos antisemitas de Heidegger, pero tienen valor para el estudio de la filosofía heideggeriana.

En este artículo nos proponemos en primer lugar tomar en consideración alguna de las circunstancias biográficas e históricas más relevantes en las que se mueve Heidegger para comprender la posición a la que llega nuestro autor alrededor de 1933. No es un comentario exhaustivo, simplemente pretende sugerir una línea de interpretación basada en la idea de que Heidegger actúa en 1933 de forma reactiva en relación a su pasado católico.

Seguidamente nos proponemos describir de la mano del primer volumen de los Cuadernos negros los principales elementos filosóficos que ocupan a Heidegger durante el período de 1931-1934. El volumen publicado por Klostermann ocupa el período de 1931-1938 pero nosotros restringiremos nuestra atención a los años aludidos. Con ello trataremos de responder a la pregunta de hasta qué punto los Cuadernos negros nos ayudan a comprender las tensiones y los movimientos de Heidegger en los meses inmediatamente anteriores a su acceso al rectorado, así como la percepción que tiene de su momento durante su tiempo como máximo responsable de la Universidad de Freiburg.

1. Algunas consideraciones sobre el CAmino de Heidegger hasta 1932/33:

Hugo Ott concede una justa atención a dos hechos que Heidegger menciona como especialmente determinantes en su vida ${ }^{5}$. En una carta fechada el 1 de julio de 1935 (por tanto en un momento en el que ya hacía más de un año que se había retirado de sus responsabilidades como rector de la Universidad) Heidegger habla de dos espinas que debe superar: la fe de sus orígenes (es decir, el catolicismo) y el fracaso en el rectorado.

verschaffte, ohne die verborgenen Entscheidungsbezirke von sich aus je fassen zu können.» Ebd. S. 46).

Cf. El estudio de Trawny, P., Heidegger und der Mythos der jüdischen Weltverschwörung, Klostermann, Frankfurt a.M.,, 2015, traducción española: TrawnY, P., Heidegger y el mito de la conspiración muncial de los judíos, Herder, Barcelona, 2015.

5 Cf. Отт, H., Martin Heidegger, Unterwegs zu seiner Biographie, Reihe Campus, Frankfurt a. M., 1992, p. 42. 
¿Están relacionados estos hechos? Y si lo están, ¿en qué sentido? ¿En todo caso, por qué los equipara Heidegger en 1935?

Ott sugiere que entre el alejamiento gradual de la cosmovisión católica y el hecho de depositar las esperanzas en la revolución liderada por Hitler hay algún vínculo que Heidegger no especificó nunca suficientemente. Quizás la interpretación de la relación de estos dos elementos en su biografía es relevante para llegar a hacerse cargo de la interpretación casi religiosa que hará de la revolución liderada por Hitler y de la percepción que tiene en relación con las expectativas creadas por ella.

Karl Löwith destacaba la enorme importancia que tuvo para Heidegger lo que él interpretó como la quiebra del sistema católico. Löwith habla del motivo religioso latente en los movimientos más importantes de la vida y del pensamiento del que fue su maestro ${ }^{6}$. El hecho de dejar atrás el catolicismo supuso para él la necesidad de ordenar a partir de categorías nuevas aspectos completamente fundamentales de la realidad, empezando por su misma religiosidad, su noción de esperanza, su forma de comprender el hombre, la historia, el sentido de la muerte, el sentido de la verdad y el camino que conduce a su comprensión etc.

En 1919 Heidegger habla ya de un alejamiento consolidado respecto del catolicismo en una carta a su amigo y sacerdote Engelberg Krebs. En ella, Heidegger afirma que determinadas posiciones en el orden de la teoría del conocimiento y más especialmente en la teoría del conocimiento histórico han hecho que el sistema católico le resulte problemático e inaceptable, pero añade: «no el Cristianismo y la Metafísica, aunque ésta en un sentido nuevo» ${ }^{7}$. El hecho es que su distanciación con respecto del catolicismo no significa en principio un desinterés por el cristianismo. Conviene recordar que durante los años veinte (y muy especialmente durante su estancia en Marburg, cuando se había producido ya su ruptura formal con el catolicismo) Heidegger se sintió atraído por el diálogo con teólogos de la categoría de Bultmann y que una parte importante de su producción filosófica estuvo fuertemente influida por esta proximidad con la teología protestante ${ }^{8}$. Los años pasados en Marburg y su implicación en debates con temática marcadamente religiosa dieron como fruto, entre otros, sus lecciones sobre fenomenología de la vida religiosa, un trabajo importante sobre Agustín, así como sobre la mística medieval. Es difícil negar que, a pesar de su distanciamiento en relación con el sistema católico, Heidegger mantuvo un vivo interés en relación con la temática religiosa, especialmente desde una comprensión fenomenológica ${ }^{9}$.

6 Cf. Löwith, K., Heidegger, Denker in dürftiger Zeit, Vandenhoeck \& Ruprecht, Göttingen, 1960, S. 111.

7 «... nicht aber das Christentum und die Metaphysik, diese allerdings in einem neuen Sinn». Cf. carta a Krebs del 9 de enero de 1919.

8 Cf. PögGeler, O., Philosophie und hermeneutische Theologie (Heidegger, Bultmann und die Folgen), Wilhelm Fink, München, 2009.

9 Lo más determinante de esta producción queda recogida en el volumen 60 de sus obras completas: Cf. Phänomenologie des religiösen Lebens 1. Einleitung in die Phänomenologie 
El texto de una carta que Heidegger envía a Elisabeth Blochmann contándole su paso por el monasterio benedictino de Beuron nos ayuda a entender de forma muy plástica la ambigüedad que conlleva su relación con el sistema de las confesiones y el «sentido nuevo» que da a la palabra «metafísica»:

"Aunque el catolicismo actual y sus semejantes, no menos el protestantismo, tenga que seguir siendo para nosotros una crueldad, "Beuron" (si así lo puedo llamar abreviadamente) se desplegará como una semilla de algo esencial. Esto es algo que se muestra en las Completas, que le deberían aportar más que la Eucaristía. Que el hombre termina su día en la noche es para el hombre de hoy una banalidad, si es que lo llega tomar en consideración. Ha convertido la noche en el día - el día tal y como lo concibe, esto es: como la continuación de una extrema actividad y agitación. En las Completas está la mítica y metafísica fuerza primigenia de la noche, que continuamente tendremos que atravesar, si queremos existir auténticamente. Porque el bien es sólo el bien del mal.

El hombre de hoy está bien adaptado a las organizaciones de todo tipo y para todo tipo de objetivos, pero no tiene la madurez para concentrarse en la noche. Parece que somos y que hacemos algo en el "movimiento" - pero cuando llega el reposo y la calma no sabemos qué hacer...» ${ }^{10}$.

Resulta relevante la comprensión que Heidegger tiene de su origen y formación católicos, así como de la valoración emocionadamente positiva que hará de todo ello. El texto siguiente es de 1937/38 (!): «Sin este origen teológico nunca habría ido a parar al camino del pensamiento. El origen permanece en el futuro» ${ }^{11}$. Y en otro texto Heidegger afirma en una línea parecida: "Y quien podría ignorar que la discusión con el cristianismo [me] ha acompañado calladamente durante todo este camino - una discusión que no fue ni es un "problema" incorporado, sino lo que guarda el origen más propio -la casa paterna, la patria, y la juventud (...). Solo aquel que estuvo enraizado en un mundo católico real y vivido, puede entrever las necesidades que afectan al camino actual de mi preguntar como seísmos subterráneos » ${ }^{12}$.

der Religion (Wintersemester 1920/21), Herausgeber: Matthias Jung und Thomas Regehly; 2. Augustinus und der Neuplatonismus (Sommersemester 1921); 3. Die philosophischen Grundlagen der mittelalterlichen Mystik (Ausarbeitung und Einleitung zu einer nicht gehaltenen Vorlesung 1918/19), Herausgeber: Claudius Strube, Klostermann, Frankfurt, 1995, GA 60.

10 Cf. Martin Heidegger-Elisabeth Blochmann, Briefwechsel, 1918-1969, Hrg. von Joachim W. Storck, Marbach am Neckar, 1989, S. 32. 12 September 1929. La cursiva del texto es nuestra.

11 Cf. Heidegger, Unterwegs zur Sprache, Neske, Stuttgart, 1993, p. 96.

12 «Und wer wollte verkennen, dass auf diesem ganzen bisherigen Weg verschwiegen die Auseinandersetzung mit dem Christentum mitging -eine Auseinandersetzung, die kein aufgegriffenes "Problem" war und ist, sondern Wahrung der eigensten Herkunft -des Elternhauses, der Heimat und der Jugend -und schmerzliche Ablösung davon in einem. Nur wer so verwurzelt war in einer wirklichen gelebten katholischen Welt, mag etwas von den Notwendigkeiten ahnen, die auf dem bisherigen Weg meines Fragens wie unterirdische Erdstösse wirkten». cf. «Mein bisheriger Weg» (1937/38), GA 66, p. 415. 
Quisiera subrayar el «todo» cuando se refiere a «todo este camino». Es algo que indica que, en el límite, los principios que se encuentran en la base de su determinación política en 1933 no son ajenos a los problemas generados por la discontinuidad que caracteriza su biografía espiritual y filosófica. Su voluntad de mantener el valor de su experiencia original católica y su formación teológica como elementos clave de su procedencia, gracias a los cuales ha sido posible el camino recorrido, sugiere la existencia de una continuidad de fondo más allá de la discontinuidad en las formas: "No se trata tampoco simplemente de una trasfondo "religioso" de la filosofía — escribe Heidegger-, sino de Una Pregunta por la verdad del ser, la única que decide sobre el "tiempo" y el "lugar" que históricamente mantenemos en el seno de la historia de occidente y de sus dioses» ${ }^{13}$.

A pesar de su interés por el cristianismo y por el sentido nuevo de la palabra metafísica (el sentido no platónico), no se puede infravalorar la importancia que tiene la discontinuidad con el sistema metafísico en general y con el grueso de la teología sistemática. Su ruptura con el catolicismo constituyó muy probablemente una de las maneras de enfrentarse a la gran crisis de sentido de su época. En los próximos años, Heidegger insistirá en la necesidad de asumir con todas sus consecuencias el diagnóstico de Nietzsche, en el sentido de que Dios (o al menos la comprensión metafísica-platónica de Dios vehiculada a través de la tradición) ha muerto. Hay que asumir hasta el final este hecho si queremos superar el estado de nihilismo en el que nos encontramos. Es pues importante retener que Heidegger no responde al sentimiento de crisis profunda con una tendencia restauracionista, sino todo lo contrario: su opción es marcadamente revolucionaria. Max Müller recordaba que «en el fondo no había nadie que para él [Heidegger] fuese suficientemente radical», lo que le llevó sin duda a partir del otoño de 1933 a un aislamiento notable ${ }^{14}$. Según Heidegger, nada de lo que diera continuidad a lo que hasta entonces había tenido vigencia en la cultura europea podría suponer un principio de esperanza suficiente para trascender este estado de indigencia extrema en que se encuentra Occidente. Cualquier opción de futuro que quiera superar la «muerte de Dios» no puede ignorar esta muerte, ni puede intentar encarar los nuevos retos con un material extraído de la metafísica en que se ha fundamentado el mundo occidental desde la gran revolución platónica. Hacía falta algo nuevo. Algo que supusiera una discontinuidad radical en relación a lo que hemos conocido en el pasado. Para ser más precisos: hacía falta algo original, situado más allá de la concepción metafísica del ser, es decir, de la comprensión del ser como identidad. Pocas personas vivieron el momento histórico de su generación con un sentimiento tan agudo de desmoronamiento

13 «Es handelt sich aber auch nicht um einen bloss»religiösen» Hintergrund der Philosophie, sondern um die Eine Frage nach der Wahrheit des Seins, die allein über die «Zeit» und den «Ort» entscheidet, der uns geschichtlich aufbehalten ist innerhalb der Geschichte des Abendlandes und seiner Götter». Cf. «Mein bisheriger Weg» (1937/38), GA 66, p. 415.

14 «Ein Gespräch mit Max Müller» cf. Martin, B., Martin Heidegger und das dritte Reich, Wissenschaftliche Buchgesellschaft, Darmstadt, 1989, p. 103. 
ni con la convicción de que hacía falta una transformación radical. En conexión con la necesidad de generar un pensamiento nuevo que se encontrara más allá de la tradición metafísica, añadiremos que una primera condición para que se produjera la adhesión al nacionalsocialismo por parte del autor de Ser y tiempo es que este movimiento apareciera con un potencial revolucionario capaz de iniciar una etapa histórica radicalmente nueva, liberada no sólo de las grandes fuerzas que habían construido la modernidad, sino de aquellas sin las cuales era imposible de entender Occidente desde sus inicios metafísicos. Por esta razón Heidegger comprende, como pocos en su época, el carácter mutuamente excluyente del catolicismo y del nacionalsocialismo. Ello explica que no sólo tome distancia del catolicismo, sino que durante el período de participación con el nacionalsocialismo (como veremos más adelante cuando nos refiramos a los Cuadernos negros) considere la teología y la iglesia católicas como verdaderos obstáculos para la revolución liderada por Hitler. Obstáculos a los que hay que combatir sin miramientos.

A principios de los años treinta Heidegger se siente inmerso en una realidad dolorosamente caótica. En el año 1945, recapitulando los motivos que le empujaron a asumir el cargo de rector y a sumarse al movimiento nacionalsocialista, Heidegger declaraba, en un intento de justificar su decisión: «Lo esencial es que nos encontramos en medio de la plenitud del nihilismo, que Dios ha "muerto" y que todo espacio y tiempo ha quedado cerrado para la divinidad ${ }^{15}$. Su reacción, presuntamente, estaba guiada por la necesidad de superar el estado angustioso de nihilismo en el que se encontraba Alemania y Occidente.

Verdaderamente, no podemos infravalorar la importancia de este diagnóstico. Como bien destaca Otto Pöggeler, afirmar que Dios ha muerto es una manera de poner de relieve que lo que tenía un sentido y que por tanto podía sostener el significado fundamental de la realidad y de la vida había quedado desarticulado ${ }^{16}$. Esto no sólo afecta a la capacidad del sistema teológico cristiano para fundamentar un mundo, sino también a la de los «dioses» que aspiraban a ocupar el centro mismo de la cultura: idealismo, socialismo, liberalismo, democracia, progresismo, etc. Inmerso en esta situación marcada por la ausencia de fundamentación, el hombre se ve empujado a buscar un nuevo comienzo y una nueva orientación.

Sin duda, la dimensión política de la realidad fue también uno de los elementos que quedó sin el apoyo de categorías filosóficas tradicionales y, por tanto, necesitada de una reinterpretación original. En general creemos que es oportuno ver la adhesión de Heidegger al nacionalsocialismo no sólo a la luz de la crisis del mundo europeo y alemán, sino también a la luz de la discontinuidad que para él supuso no poder orientarse a partir de las categorías fundamentales de la confesión religiosa en la que se educó.

15 Heidegger, M., Das Rektorat 1933/34 (Tatsachen und Gedanken), Klostermann, Frankfurt, 1990, 2a edición, p. 39.

16 Pöggeler, Otto, Philosophie und Politik bei Heidegger, K. Alber, Freiburg/München, 1974, p. 19. 
Hasta 1933 Heidegger había trabajado en un entorno universitario caracterizado aún por una tradición académica muy especulativa y, en muchos casos, intencionadamente alejada del debate político. Era una tradición seguramente muy elitista, un hecho que se dejaba notar de una manera muy especial precisamente en estudios como los de filosofía o filología clásica en que la aplicación práctica de los conocimientos era menos evidente que en otras especialidades. Inesperadamente, sin embargo, Heidegger demuestra en 1933 que el diagnóstico que había formulado en clave filosófica en años anteriores en relación a las consecuencias del «olvido del ser» daba pie también a una lectura política de gran alcance. La necesidad de repensar la verdad más allá de las grandes decisiones de la metafísica occidental, la percepción de lo que había tenido autoridad hasta entonces como algo obsoleto y sin apoyo en las auténticas necesidades del momento, tenía de repente una extensión política sorprendente.

En este sentido, Habermas destacaba en su momento: «En el libro El discurso filosófico de la modernidad defendí la tesis de que Heidegger hacia el 1933, y quizás incluso antes, había interpretado decididamente de otro modo conceptos fundamentales [descritos en] Ser y tiempo; hasta entonces había interpretado el concepto de "Dasein", que para él es la manera de referirse a la existencia humana, en el sentido de la filosofía de Kierkegaard, esto es en el sentido de un Dasein individual; hacia el 1933 parece que cambie este sentido: el Dasein es la forma de existir de un colectivo (...) especialmente de un pueblo, que ahora en su autoafirmación internacional proyecta su propio destino. A través de este cambio de interpretación hace aparecer políticamente toda la conceptualización de Ser y tiempo en una nueva luz» ${ }^{17}$.

Tras esta breve contextualización, nos proponemos a continuación una lectura del primer volumen de los Cuadernos negros con la intención de explorar el tratamiento que reciben los temas a los que hemos aludido. La publicación reciente de estos textos justifica un análisis que nos pueda ayudar a enriquecer y a detallar el sentido de los «seísmos subterráneos» de los que habla Heidegger.

\section{LOS PRIMEROS CUADERNOS NEGROS}

Con la aparición del volumen 94 de las Obras Completas de Heidegger, la editorial alemana Vittorio Klostermann inició en 2014 la publicación de los llamados Cuadernos negros. Según el programa de la editorial, la publicación de los treinta y cuatro cuadernos, que cubren des de principios de los años treinta hasta principios de los setenta, ocupará un total de nueve volúmenes (del volumen 94 al 102). A fecha de hoy, se ha publicado hasta el volumen 97.

17 Cf. Habermas, Jürgen, Philosophisch-politische Profile, Frankfurt am Main 1971, pág. 171-172. 
El conjunto del volumen publicado abarca el período de 1931 al 1938, articulados en cinco 'Reflexiones' (Überlegungen), de la número II a la número $\mathrm{VI}^{18}$. Por el momento se desconoce el paradero de la Reflexión número $\mathrm{I}^{19}$. En estas páginas que siguen nos limitamos a tomar en consideración principalmente las dos primeras partes o reflexiones de los cuadernos aparecidos en el primero de los volúmenes citados, aquellas que se centran en los años 1931-1934.

A lo largo de estos cuadernos los textos de Heidegger no siguen una estructura temática convencional, en el sentido de que tengan un despliegue articulado en la forma de una exposición sistemática. Sin embargo, el número de temas que aborda el autor de manera más o menos recurrente es limitado o en todo caso sus aportaciones se agrupan alrededor de determinadas cuestiones que dan una continuidad de fondo fácilmente reconocible. Estas reflexiones no son un diario más o menos íntimo, ni anotaciones más o menos espontáneas, sino expresiones filosóficas bien calibradas a las que Heidegger reservó el lugar final en la serie de volúmenes de sus obras completas. Por otra parte, el trasfondo histórico y biográfico está presente de una forma clara en numerosas entradas.

\subsection{Señas $X$ Reflexiones (II) e indicaciones (Octubre de 1931)}

La valoración que se desprende de las páginas de la primera y de la segunda reflexión de Heidegger en relación a su momento histórico es ambigua. Por una parte está la conciencia de vivir inmerso en las múltiples e insufribles consecuencias del nihilismo. Por otra parte, hay indicios en el horizonte que permiten abrir unos resquicios de esperanza.

En relación a la comprensión de la situación de su cultura como escenario múltiples manifestaciones de un nihilismo fundamental, querríamos destacar en primer lugar un elemento de estilo que conlleva una disposición de fondo; nos referimos al tono agrio y a menudo implacable utilizado por Heidegger, con juicios de una gran dureza dirigidos a los protagonistas de su momento histórico en el mundo de la cultura y, muy particularmente, en el mundo de la filosofía. Lejos de buscar puntos de encuentro o zonas de intersección con otros autores o escuelas, Heidegger arremete de una forma diríamos casi amarga contra todo su entorno y contra todo aquello que lleva el signo de la contemporaneidad. Heidegger vive el sentimiento de encontrarse en medio una decadencia dolorosa y angustiante, tiene una percepción de su tiempo como

18 Heidegger, M., Überlegungen II-VI (Schwarze Hefte 1931-1938), GA Bd. 94, Vittorio Klostermann, Frankfurt am Main, 2015. Hay traducción (i) inglesa: Ponderings II-VI (Black Notebooks), Indiana University Press, 2016; (ii) española: Cuadernos negros (1931-1938), Trotta, Madrid, 2015. Para los textos citados en nuestro artículo utilizamos la traducción que aparece en la edición española de Trotta.

19 Según la información facilitada por la editorial Klostermann, la familia Heidegger supone que éste dejó a alguien dicho cuaderno y no lo logró recuperar jamás. Cf:

http://www.klostermann.de/epages/63574303.sf/de_DE/?ObjectPath=/Shops/63574303/ Categories/Buecher/Philosophie/\%22Martin\%20Heidegger\%22/Gliederung_der_HGA, consultado el 3 de agosto de 2016. 
algo profunda e insoportablemente marcado por el nihilismo y sus numerosas consecuencias.

Hay que añadir a este Kulturpessimismus un sentimiento pesante de soledad. Hace ya más de cuatro años de la publicación de Ser y tiempo. Heidegger recapitula la recepción de su libro durante estos años y constata que, a pesar del éxito obtenido y la notoriedad alcanzada, nadie lo ha comprendido. Este hecho no se puede interpretar simplemente aludiendo a una cierta complejidad temática o a ciertos malentendidos en el uso de conceptos filosóficos originales. Es algo que tiene un significado más profundo. Heidegger escribe en marzo de 1932: "Desde luego que hasta hoy nadie ha comprendido este camino [el que él ha transitado]; nadie ha avanzado ni ha retrocedido por él; es decir, nadie ha intentado rechazarlo. Para eso habría sido necesario entender el "objetivo", o diciéndolo más precavidamente, el espacio (el “ahí”) al que el camino pretendía conducir y trasladar. Pero eso no ha sucedido. Y sin embargo, todo habla a gritos sobre la "ontología”, como si ella fuera algo que todos conocen» [II, 49]20.

Nadie ha llegado a una visión suficientemente original de la pregunta como para comprender el sentido de su análisis. Peor aún: «Al fin y al cabo, el horrible "éxito" [de Ser y tiempo] ha consistido solo en que ahora se chacharea todavía más y aún con más desfachatez y menos fundamento acerca del "ser"” [II, 14]. O bien: "El fracaso: ni con Ser y tiempo ni con el resto de los textos se ha logrado en lo más mínimo siquiera apremiar en dirección al preguntar, por no decir ya acabar gestando una comprensión de la pregunta que conduzca a un preguntar reiterado. En lugar de eso, nada más que un parloteo desencaminado» [II 126].

Según se desprende de la perspectiva de Heidegger, el hecho de que no se comprenda su pensamiento no es algo azaroso. Es más bien un fenómeno muy significativo y muy coherente con el diagnóstico que elabora el autor: su época no tiene la madurez que se requiere para llegar a la comprensión de la pregunta por el ser, porque «ni están en condiciones de saber manejar la forma interna y viva toda la auténtica historia de la dicha pregunta, ni tampoco están a la altura de la fuerza esencial que tiene esta pregunta para acometer las posibilidades de la existencia (arte, fe, naturaleza)». Pero no es solo la comprensión de la pregunta por el ser lo que resulta inasequible para su época. Hay que añadir: «Aún menos fuertes son los tiempos para aquello que, en realidad, la pregunta por el ser se limita a preparar: su superación, en el sentido de un verdadero volver a comenzar con el comienzo (Wiederanfangs mit dem Anfang)» [II, 22]. La incapacidad para comprender el pensamiento expuesto en Ser y tiempo, Qué es metafísica, sus lecciones sobre Kant, Sobre la esencia del fundamento I y II pone de relieve, pues, algo esencial de su momento histórico. Heidegger se referirá a ello cuando hable de su época como: La época de la completa ausencia de cuestionamiento de todas las cosas... (gänzlichen Fraglosigkeit aller Dinge) (V, 2). Es decir: la época que es incapaz de aunar las energías para llegar

20 Entre paréntesis indico el número de la reflexión en cifras romanas, seguidamente, en cifras árabes, el número del parágrafo o entrada. 
a la posibilidad de interrogarse en relación a lo esencial. «No somos lo bastante fuertes ni originarios como para "hablar" verdaderamente guardando silencio y a causa del temor (um durch Schweigen und Scheu wahrhaft zu "reden"). Por eso resulta que hay que hablar de todo, es decir, parlotear» (II, 15).

Esta es una de las formas principales en las que se concreta el estado de nihilismo propio de nuestra civilización. Una civilización en la que prevalece por todas partes y desde hace mucho tiempo «la falta de fuerzas para una estimulación del ser que nos dé indicaciones» [II, 153]. El nihilismo que arroja al hombre a la incapacitación para la pregunta por el ser es el que está en la base del sentimiento de encontrarse en un final. En la Reflexión V se pregunta Heidegger: "¿Por qué el hombre se empequeñece cada vez más?». La respuesta: "porque se deja vedado el margen de espacio para crecer hasta la grandeza, boicoteando la fundación de este espacio» [V, 36]. El sentimiento que domina a Heidegger en estas páginas es, como hemos ya apuntado, el de vivir inmerso en una exasperación de la nada; el de la completa ausencia de capacidad para vivir humanamente: jamás las generaciones anteriores «estuvieron tan al borde de la nada como nosotros» [II, 111].

Ante esto cabe solo una defensa hasta el final de lo esencial [II, 112], que Heidegger concretará con una apelación a la capacitación del ser (Ermächtigung des Seins) y a la necesidad de retomar la pregunta fundamental por el ser. Pero la pregunta por el ser no surge simplemente de una exposición sistemática de lo que ya se ha dicho en filosofía; no se trata simplemente de un "tema» o de un juego más o menos académico, sino de una decisión de ruptura con el pasado metafísico. La pregunta por el ser no se mueve en el ámbito de la corrección, sino en el de la verdad (cf. II, 136), porqué «La esencia del ser es la verdad $\dot{\alpha} \lambda \hat{\vartheta} \vartheta \varepsilon 1 \alpha) »$. [II, 133].

Esta es la prioridad: si no somos capaces de volver a empezar por el principio de la filosofía occidental, entonces el final resulta inevitable [II, 134]. Nunca como ahora la filosofía había necesitado de la «sencillez, la esencialidad y la originalidad» [II, 134], nunca como ahora, cuando el nihilismo aflora con toda su fuerza, nos hace falta resituarnos en el gran comienzo [II, 138].

Pero hay obstáculos para ello; hay fuerzas de gran calado que lastran la posibilidad de esta vuelta al preguntar esencial e impiden con ello abrirse a la necesidad más apremiante de nuestro mundo. Heidegger se refiere a: (a) la trivialización de la comprensión antigua del ser «que ya se había superficializado y enajenado en la cosmovisión cristiana» y su consiguiente secularización y (b) la matematización del saber, la importancia de la certeza y "por eso que se da en llamar demostrabilidad y objectividad» [II 141]. Es decir, por una parte, la metafísica y sus consecuencias históricas materializadas en la teología y en el pensamiento ontológico moderno; por otra parte, el saber científico moderno y su tendencia a la objetivación de la verdad y a su determinación como universalidad. En general, toda filosofía que se apoye en la ontología pierde la posibilidad de interrogar el ser, especialmente porque el $\lambda$ ó permite el acceso al ǒ $\tau \tilde{i}$ ó $\tau$. [II, 220]. Así pues, la solución a la situación actual no puede vehicularse ni por la vía de una fuga en la fe (el cristianismo aparece 
en estas páginas como un refugio insostenible, como algo que se ha vaciado de contenido) ni por la vía de la confianza en el racionalismo y en su tecnología. Por esta razón el acceso a un nuevo comienzo tendrá que ser el resultado de una lucha (Kampf) [II, 160].

Aquí hay una misión alemana: acabar con la filosofía de la manera que se ha comprendido hasta hoy; afrontar este hundimiento sin caer en una huida "a la fe o a algún tipo de feroz ceguera, aunque sea siquiera la de la racionalización y la tecnificación» [II, 168].

Aquí ve Heidegger la tarea principal: superar radicalmente el estar perdido en medio del ente como expresión del olvido del ser por medio de un rechazo de toda mediación que provenga tanto del cristianismo como de la metafísica. Superar radicalmente, decimos: ni siquiera Nietzsche aborda la necesidad de una pregunta radical con la suficiente ambición; incluso el autor de La gaya ciencia se mueve dentro de las posibilidades ofrecidas por el cristianismo cuando afirma que «Dios está muerto» [II, 186] o dentro de las posibilidades de la metafísica cuando afirma el devenir frente al ser [II, 132].

Lo cierto es que después de todo el s. XIX y sus aparentes transformaciones radicales «Todo siguió como estaba antes» [II, 132]. La tarea, por lo tanto, es ingente y sin puntos de apoyo en el pasado inmediato, dado que nadie parece haberse percatado de la urgencia de dar respuesta a este dolor derivado del nihilismo.

Además, es, repetimos, una cuestión alemana, porqué «solo a él [el alemán] le está aguardando la asunción de la lejana disposición del comienzo» [II, 224]. Heidegger apunta ya en las Reflexiones $\mathrm{II}^{21}$ (escritas entre octubre de 1931 y el otoño de 1932) que el volver a comenzar no es una mera reanimación de la Antigüedad, sino una reanimación de «nuestro pueblo y de su misión» [II, 237]. El pueblo (Volks) se encuentra ante una misión fundamental de la que va a depender la posibilidad de un inicio radicalmente nuevo.

La verdad es que no encontramos razones en las páginas de Heidegger que permitan sostener esta posición que se mantiene una y otra vez a lo largo de los Cuadernos. ¿Por qué Alemania? ¿Cuáles son los sobreentendidos de esta afirmación que quedan sin la necesidad de una explicación? ¿De dónde surge la exclusividad de esta misión?

Casi subrepticiamente se abre a lo largo de las Reflexiones II toda una dimensión política de la lectura que Heidegger hace de su tiempo y de sus necesidades de fondo.

\subsection{Reflexiones y señas III}

Sorprende constatar que las Reflexiones III, cuyas páginas, según consta en el inicio, fueron redactadas a partir del otoño de 1932, dejen prácticamente sin cubrir el periodo de septiembre/octubre de 1932 hasta el marzo/abril de

${ }^{21}$ Cf. Señas x reflexiones (II) e indicaciones. 
1933. De las noventa páginas que ocupan las terceras reflexiones en la versión alemana, sólo un máximo de dos podrían haberse escrito antes de marzo de 1933. Dicho de otra manera: del total de 219 entradas, tan solo 7 podrían haberse redactado antes de haber recibido la invitación a asumir el cargo de rector, dado que en la entrada 8 Heidegger se refiere ya de forma explícita a esta cuestión ( «Habiéndoseme apremiado a que asuma el rectorado...» [III, 8]). Por otra parte, teniendo en cuenta que las Reflexiones IV llevan la datación de 1934/1935, debemos concluir que las Reflexiones III se elaboran prácticamente en su totalidad en el año 1933 después de la toma de poder por parte de Hitler el 30 de enero. No encontramos pues en los Cuadernos negros de Heidegger prácticamente ninguna página que nos indique algo sobre la evolución del autor en los meses inmediatamente anteriores a la Machtergreifung ni sobre su posicionamiento ante la inminente toma de poder por parte de los nazis. Con ello, quedan abiertas preguntas como: ¿por qué Heidegger presta tan poca atención a sus Cuadernos precisamente durante esos meses en los que se producen en Alemania motivos suficientes para reflexionar sobre acontecimientos de gran envergadura que pueden dar un encuadre político a su análisis? Quizás ello pone de relieve que su aislamiento durante el semestre de invierno de 1932/33, propiciado por el permiso que obtiene de la Universidad para quedar eximido de toda carga docente, fuese realmente muy intenso y que, en consecuencia, ya antes de octubre de 1932 Heidegger fuese visto por miembros influyentes de la Universidad como alguien afín a la futura (y por aquel entonces incierta) revolución.

Sea como sea, con el inicio de las Reflexiones III y a pesar del escepticismo en relación a la capacidad per acometer esta «más íntima y extrema misión del alemán» [II, 168] Heidegger ve en el horizonte signos de esperanza. La primera entrada de la Reflexión III expresa la ambigüedad a la que nos referíamos al inicio de nuestro comentario de los Cuadernos: "Una voluntad popular que despierta en toda su magnificencia sigue todavía dentro de una enorme oscuridad universal» [III, 1]. Parece difícil negar la participación de Heidegger en el entusiasmo generado por las nuevas expectativas políticas cuando habla, por ejemplo, de la existencia alemana como algo que «está despertando hasta su grandeza oculta y que la está aguardando, hasta esa grandeza entorno de

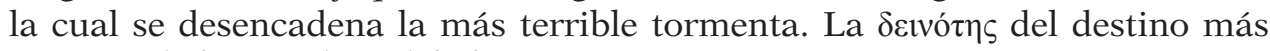
extremo de la grandeza del alemán» [III, 5].

Con esto hemos hecho alusión a dos de las siete entradas que se supone puede justificar que las Reflexiones III se empezaran a redactar en otoño de 1932. Es difícil delimitar las consecuencias de esta circunstancia, en todo caso ponen de relieve que las preocupaciones formuladas en los meses anteriores al otoño de 1932 dan paso ahora a una visión esperanzada en relación a lo que pueda ocurrir en el futuro. Parece por tanto razonable afirmar que Heidegger no 'descubre' el nacionalsocialismo después del 30 de enero de 1933, ni Hitler supone para él una novedad ante la cual no sabe muy bien cómo reaccionar.

En los primeros momentos de su cargo como rector, el tono de euforia se desencadena; hay consciencia de encontrarse ante una hora fundacional: «La 
gran experiencia y el gran motivo de dicha es que el Führer ha despertado una nueva realidad que da a nuestro pensamiento el cauce y la fuerza de choque (Stosskraft) correctas» (III, 10).

Consideramos que esta es una expresión de gran calado. En ella creemos que se dan muestras de la confianza que revolución política y pensamiento filosófico podrán aunar sus fuerzas en una misma dirección. En todo caso, pone de relieve que Heidegger no percibe el acontecer político como un mero hecho de estado ni siquiera como el final de un determinado encaje nacional e internacional de Alemania en el sistema surgido de Versalles. La revolución no es ajena a la misión fundamental de los alemanes, y por lo tanto no es para nada ajena a la responsabilidad fundamental que tiene la filosofía en el nuevo contexto.

Hay numerosos fragmentos que parecen dar la razón de una manera difícilmente contestable a las observaciones de Habermas que más arriba hemos citado. En efecto, determinados conceptos clave que Heidegger había introducido en 1927 adquieren en el nuevo contexto histórico de 1933 una significación política que nadie hubiera imaginado anteriormente. Heidegger escribe: "Conforme a su ensambladura más íntima, la metafísica de la existencia (Die Metaphysik des Daseins) tiene que ahondarse y ampliarse en una metapolítica "del" pueblo histórico» (III, 54). La descripción fenomenológica de la existencia que preparaba la pregunta por el ser se ahonda en este contexto en una nueva forma de concebir el Dasein como 'pueblo'. Esto es algo, insistimos, que en 1927 nadie estuvo en condiciones de prever. En este nuevo contexto biográfico e histórico se despliega una nueva dimensión de la necesidad de la ruptura con la metafísica como expresión del olvido del ser.

El Dasein alemán no puede estar sujeto a una dirección basada en ideas y teorías; no es lo universal concebido como pensamiento conceptual o como cosmovisión aquello que puede dar una orientación a la existencia alemana. El sentido del tiempo lo tiene que dar una misión (Auftrag). «El esbozo del ser como tiempo supera todo lo que había hasta ahora en el ser y en el pensar. No una idea, sino una misión». No se trata de desapegarse para convertirse en un espíritu puro, sino para permitir una vinculación de la sangre (Blut) con el suelo (Boden) [III, 61].

Heidegger no tardará demasiados meses en comprender que el rechazo a la metafísica como elemento que genera ideas es interpretado en ambientes muy influyentes y próximos a la dirección de la «revolución» como un motivo para deshacerse de la filosofía en todo su conjunto. No hallará una disposición para un pensamiento fundacional, sino simplemente el deseo de liberar la acción de toda teoría que condicione la voluntad. Será una de les múltiples manifestaciones de lo que Heidegger califica a lo largo de los Cuadernos negros de «nacionalsocialismo vulgar» [III, 81]. Es cierto, sostiene Heidegger, que el nacionalsocialismo no es una «Teoría», pero se ignora el sentido ambiguo de esta palabra si se pretende convertir el nacionalsocialismo en un mero activismo sin orientación en la realidad: "No hay que mezclar "teoría" como mero pensamiento desapegado, con la "teoría" como una exigencia anticipatoria del saber» [III, 69]. 
En estos meses dramáticos, los Cuadernos dan muestra de la decisión de Heidegger de discernir entre la necesidad de una destrucción sin cuartel de todo lo que ha sostenido el mundo que ha acabado en el nihilismo y la necesidad de proteger lo que él llama el «nacionalsocialismo espiritual» (!) [III, 72]. Ahí es donde el nacionalsocialismo tendrá que luchar contra el oportunismo, contra la posibilidad de aburguesarse, de negar su carácter radicalmente revolucionario y por lo tanto de degradarse en la forma de la vulgaridad y la mediocridad: «El radicalismo de un movimiento solo se puede conservar ahí donde constantemente tiene que volver a ser creado de la forma más clara y profunda: en lo espiritual» [III, 74]. "Lo fundamental del nacionalsocialismo no reside en el hecho de que sea una respuesta a la precariedad (Not) económica (el paro) o a la precariedad histórica (Versalles). Hay una precariedad más esencial que justifica el acontecer de la revolución, esto es: la precariedad existencial espiritual (geistige Daseinsnot), la cual se convierte en la máxima precariedad precisamente porque no se tiene aún la suficiente grandeza para experimentarla ni sufrirla» [III, 88]. Pero esto es justamente lo que nadie parecerá dispuesto a comprender y menos aún defender.

Heidegger se ahoga en la Universidad por la presión de diferentes frentes. La universidad a la que él quería imprimir un sentido revolucionario para convertirse en la institución que a través de su “Autoafirmación” impulsara una nueva ciencia alemana, sigue en manos de organizaciones (la "federación nacionalsocialista de médicos», la «federación nacionalsocialista de abogados», «federación nacionalsocialista de profesores», etc.) que actúan con criterios estrictamente corporativistas. Se trata de organizaciones impermeables a toda instrucción política o filosófica que continúan velando por los mismos intereses burgueses y mediocres de antaño pero con medios oficialmente diferentes. Nadie parece comprender que el control que ejercen estas organizaciones en los destinos de la universidad y la indiferencia de las instituciones de gobierno para con ellas ponen en peligro la transformación de los estudios superiores $\mathrm{y}$, consiguientemente, la posibilidad de educar la juventud alemana de una manera radicalmente diferente.

Heidegger percibe ya la posibilidad de que una desconexión entre el nacionalsocialismo y las inercias culturales lleven la revolución al fracaso. Esta sensación es creciente a medida que pasa el tiempo. La universidad sigue en manos de los que no han comprendido que el nacionalsocialismo es un movimiento de choque y de lucha que, en esta misma medida, permite crear el entorno para la correcta comprensión del saber. Pues el saber es una lucha: no es posible llegar al saber de la verdad sin haber dejado la seguridad de las cosmovisiones, sin abandonar la comodidad de las posiciones teóricas que se aceptan por el mero hecho de que proporcionan seguridad y refugio [V, 33]. De acuerdo con esta comprensión, la lucha del saber implica estar en condiciones de determinar dónde se encuentra el enemigo y dónde está el frente. No habrá transformación de la universidad ni de las nociones de ciencia y de verdad mientras siga prevaleciendo la cultura burguesa, es decir, aquella que busca a todo precio la tranquilidad y la comodidad, la que es incapaz de determinar 
quién es el enemigo y de concebir la existencia y el saber como riesgo o inseguridad [IV, 169].

El enemigo no es pues sólo la reacción y las confesiones cristianas. También las organizaciones y toda la mediocridad que consigo acarrean y que trasladan al nacionalsocialismo un elemento de vulgaridad con el que se ponen en peligro las grandes posibilidades de la revolución [III, 71; III 169].

En abril de 1934 Heidegger no tiene dudas ya sobre la imposibilidad de imprimir a su puesto de rector de la Universidad el sentido que él quisiera darle. En su discurso de despedida (del 28 de abril de 1934) reconoce en buena parte lo inútil de su implicación [III, 101]. El sentido de la Autoafirmación sólo podía sostenerse si en la universidad hubiese existido la suficiente determinación para un nuevo comienzo y una recuperación (Rückgewinnung) del propio ser [IV, 257]. El persistente interés por una ciencia nihilista y por su consiguiente incapacidad para abordar lo más digno de ser interrogado (das Fragwürdigste) arrastran a la universidad a la precariedad máxima y con ello hacen imposible cualquier transformación. Heidegger se retira de la máxima responsabilidad con el sentimiento de fracaso, y sin embargo insiste (1934) en que su lugar sigue siendo la lucha en el frente ( $P$ Permaneceremos en el frente invisible de la Alemania espiritual secreta» [III, 101]).

La ausencia de un preguntar fundamental, el miedo a la meditación [V, 33/34], la incapacidad de tener la grandeza necesaria para llegar a sufrir la precariedad espiritual... todo ello se acabará por imponer en la interpretación que Heidegger hace de su entorno. Ni el siglo XIX cambió nada; ni tampoco parece que vaya a cambiar nada en el s. XX. Solo así podemos explicar «lo que está sucediendo»: "La destrucción de la tierra: el alternativo acecharse de los pueblos y el hacer negocios sin sentido ni objetivo, sin la voluntad de un objetivo...» [V, 3]. Su compromiso público con el nacionalsocialismo ha sido en vano. Heidegger se retira de nuevo para no ser arrastrado por la tendencia dominante a «la incesante degradación de todo lo inicial y original» [III, 123].

\section{ConCLusiones}

El distanciamiento de Heidegger respecto del cristianismo y la constatación del final de la metafísica occidental no se cierran con el descubrimiento de otra cosmovisión, sino con el sentimiento de estar en la indigencia, errando en la búsqueda de una verdad (II, 23). La necesidad de un nuevo comienzo expresa la discontinuidad con los valores de su formación a la vez que condiciona su actitud en relación a soluciones revolucionarias. Los Cuadernos ${ }^{22}$ ponen de relieve que a principios de los años treinta Heidegger es un pensador

22 Se entiende: la parte de los Cuadernos negros que hemos tomado en consideración en este artículo. 
concentrado en abordar la tarea de la fundamentación de un nuevo principio que dé respuesta al dolor nihilista del mundo moderno.

Los Cuadernos ayudan a entender que la búsqueda de un nuevo principio no es ajena a lo que Heidegger habría trabajado anteriormente y que había culminado en 1927. Heidegger se hace eco del hecho que Ser y tiempo se ha interpretado principalmente en el marco de una Existenzphilosophie. Una de las razones que explican el sentimiento de incomprensión en el que vive Heidegger después de la publicación de Ser y tiempo es precisamente que nadie haya sabido poner este libro en conexión con la necesidad de fundamentar un principio que deje atrás el mundo surgido del olvido del ser. Quizás lo que no se ha entendido es precisamente lo que permite interpretar correctamente la actitud de Heidegger en 1933. En ese año se puede ya apreciar el despliegue y el alcance de aquella pregunta que incluye derivadas políticas e institucionales de primera magnitud. Heidegger da muestras de percibir el nacionalsocialismo como la revolución que puede allanar el camino a una superación del nihilismo en Alemania y, por lo tanto, a la superación de todas las creencias en las que se ha sostenido Europa. Con ello, los Cuadernos, aunque no ofrezcan ninguna luz sobre los movimientos de aproximación de Heidegger al nacionalsocialismo durante los meses inmediatamente anteriores a la Machtergreifung, sí que facilitan la posibilidad de comprender la conexión de Ser y tiempo y la incorporación de su autor a la revolución hitleriana.

Universitat Ramon Llull

IGNASI BOADA

Facultad de Comunicación y Relaciones Internacionales

ignasibs@blanquerna.url.edu

[Artículo aprobado para publicación en diciembre de 2016] 